PONTIFÍCIA UNIVERSIDADE CATÓLICA DO RIO DE JANEIRO

Os desafios e as motivações para a contratação de planos funerários

Camilla Queiroz Castilho

Trabalho de Conclusão de Curso

Centro de CIÊnCIAS SOCIAIS - CCS

Departamento de AdMINISTRAÇÃo

Graduação em Administração de Empresas 
Camilla Queiroz Castilho

\section{Os desafios e as motivações para a contratação de planos funerários}

Trabalho de Conclusão de Curso

Trabalho de Conclusão de Curso, apresentado ao programa de graduação em Administração da PUC-Rio como requisito parcial para a obtenção do título de graduação em Administração.

Orientador(a): João Renato de Souza Coelho Benazzi

Rio de Janeiro, novembro de 2021. 
Dedicatória

Dedico essa monografia à uma pessoa que não pôde acompanhar de perto essa minha trajetória, mas que foi extremamente essencial na minha vida. À minha eterna incentivadora e exemplo de ser humano: Tia Heloisa, eu te amo pra sempre. 


\section{Agradecimentos}

À minha família de modo geral, pela energia positiva, pelo apoio e incentivo durante os meus anos de estudo.

Aos meus pais, Adriano e Denise, pelos esforços, sacrifícios e por me proporcionarem a oportunidade de estudar em instituições de qualidade, para que essa etapa pudesse ser concluída. Essa conquista também é deles.

À minha irmã, Beatriz, por ser luz na minha vida, pelo apoio incondicional, que sempre esteve ao meu lado me incentivando e vibrando a cada conquista minha, e agora mais ainda, com a conclusão desta etapa.

A todos meus amigos, que estiverem presentes e que me deram forças durante essa trajetória, especialmente, Luana Policarpo e Carolina Oliveira, que dividiram comigo essa caminhada de companheirismo desde o início da faculdade e que foram fundamentais para minha formação.

Ao meu namorado, Fábio, que mesmo chegando ao final dessa trajetória, fez uma enorme diferença, me dando confiança e força para seguir em frente, dia após dia, e por ter sido parceiro e paciente.

Ao meu orientador, João Renato Benazzi, que apesar da intensa rotina de sua vida acadêmica aceitou me orientar nesta monografia. As suas contribuições fizeram toda a diferença. Obrigada.

A todos que participaram das pesquisas, pela colaboração e disposição no processo de obtenção de dados.

Por fim, a mim mesma, por nunca ter desistido, por ter encarado as minhas inseguranças, por ter acreditado na minha capacidade e por conseguir enxergar os meus limites. 


\section{Resumo}

Castilho, Camilla. Os desafios e as motivações para a contratação de planos funerários. Rio de Janeiro, 2021. Número de páginas 33 p. Trabalho de Conclusão de Curso - Departamento de Administração. Pontifícia Universidade Católica do Rio de Janeiro.

O intuito desta pesquisa visou compreender as diversas percepções das pessoas que possuem o plano funerário e também daquelas que não possuem em relação a esse mercado, ou seja, quais foram as motivações e os desafios durante o processo de decisão de compra. Além disso, foi abordado também uma visão mais estratégica, com a participação de um empresário influente no mercado funerário. Para isso, foram realizadas pesquisas qualitativas individuais, com a finalidade de captar informações e opiniões profundas dos entrevistados sobre sentimentos, sensações e experiências no mercado funerário. Paralelamente, foram abordados os conceitos do comportamento do consumidor para conceder base à pesquisa.

Palavras- chave

Plano funerário, comportamento do consumidor, mercado funerário. 


\section{Abstract}

Castilho, Camilla. The challenges and. Motivations for hiring funeral plans. Rio de Janeiro, 2021. Número de páginas 33 p. Trabalho de Conclusão de Curso - Departamento de Administração. Pontifícia Universidade Católica do Rio de Janeiro.

The purpose of this research was to understand the different perceptions of people who have the funeral plan and also those who do not have in relation to this market, that is, what were the motivations and challenges during the purchase decision process. In addition, a more strategic vision was also addressed, with the participation of an influential businessman in the funeral market. For this, individual qualitative surveys were carried out, with the purpose of capturing information and deep opinions of the interviewees about feelings, sensations and experiences in the funeral market. At the same time, the concepts of consumer behavior were addressed to base the research.

\section{Key-words}

Funeral plan, consumer behavior, funeral market. 


\section{Sumário}

1. Introdução 1

1.1. Contextualização 1

1.2. Objetivo do estudo 2

1.3. Delimitação e foco do estudo 2

1.4. Relevância do estudo 2

2 Referencial Teórico 4

2.1. Processo de decisão de compra 4

2.1.1. Modelo de etapas 4

2.1.2. As três categorias de tomada de decisão do consumidor 9

$\begin{array}{ll}\text { 2.1.2.1 Cognitiva } & 10\end{array}$

2.1.2.2 Habitual 12

$\begin{array}{lll}2.1 .2 .3 \text { Afetiva } & 12\end{array}$

2.2. Análise de mercados consumidores 13

$\begin{array}{ll}\text { 2.2.1. Fatores culturais } & 13\end{array}$

2.2.2. Fatores sociais 13

2.2.3. Fatores pessoais 14

$\begin{array}{ll}\text { 2.2.4. Fatores psicológicos } & 15\end{array}$

3 Métodos e procedimentos de coleta e de análise de dados do estudo 17

3.1. Etapas de coleta de dados 17

3.2. Fontes de informação selecionadas e os procedimentos de coleta de $\begin{array}{ll}\text { dados utilizados no estudo } & 17\end{array}$

3.3. Formas de tratamento e análise dos dados coletados 18

3.4. Limitações do Estudo 18

4 Apresentação e análise dos resultados 19

4.1. Descrição do perfil dos entrevistados 19

4.2. Análise dos resultados do grupo que não possui plano funerário 20

4.3. A Análise dos resultados do grupo que possui plano funerário 23 
5 Conclusões e recomendações para novos estudos

\section{Lista de figuras}

Figura 1: Modelo das cinco etapas do processo de decisão de compra do

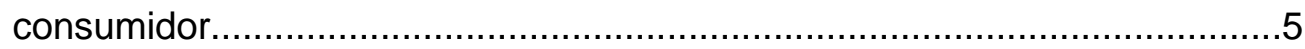

Figura 2: Etapas entre a avaliação de alternativas e a decisão do consumidor....8

Figura 3: Os três recipientes da tomada de decisão do consumidor......................9

Figura 4: Envolvimento e tomada de decisão.................................................10

Figura 5: Mudanças no estado real e ideal...................................................11

Figura 6: Pirâmide de hierarquia das necessidades de Maslow.........................15

\section{Lista de Tabelas}

Tabela 1: Perfil dos participantes entrevistados 


\section{Introdução}

\subsection{Contextualização}

Com a pandemia, que está presente desde o final de 2019, diversos setores foram impactados pelo coronavírus, inclusive, o setor funerário. Enquanto, muitos imaginam que o setor funerário está obtendo resultados favoráveis com a Covid-19, o presidente da Associação de Empresas e Diretores do Setor Funerário (Abredif), Lourival Panhozzi alerta "A situação está num ponto muito crítico, nosso setor está sendo testado ao limite, várias regiões já estão trabalhando na capacidade máxima. Se não houver contenção de casos, teremos um cenário muito preocupante" (Andrade, 2021).

Sob outra perspectiva, com a crescente necessidade do serviço funerário, o mercado de planos funerários vivenciou um considerável crescimento com a pandemia, em consequência do aumento do número de óbitos causados pelo coronavírus. Dessa forma, a população passou a procurar pelos planos funerais. Segundo a diretora de Recursos Humanos do Grupo Memorial, Patrícia Meireles (Borges, 2021), nos últimos meses, realmente, houve um progresso na quantidade de contratação de planos funerários, mas também ocorreu um aumento nos custos, devido ao alto crescimento das despesas de materiais e da utilização dos serviços do plano (Borges, 2021).

Dessa forma, o mercado funerário tem, mesmo em meio a um cenário, totalmente atípico, uma oportunidade de atingir um elevado número de novos clientes, já que, houve um aumento significativo das contratações de planos funerais, por causa da pandemia (Borges, 2021). Entretanto, as empresas funerárias precisam estar atentas ao mundo pós-surto hodierno, onde pode suceder o efeito reverso, que consiste no cancelamento desses planos adquiridos durante este período. Ou seja, as organizações têm a necessidade de elaborar estratégias para a retenção desse público, visto que, o ramo enfrentará este desafio.

Entretanto, existe uma desorientação quanto a distinção entre um seguro de vida e um plano funerário, provocando a falsa sensação de que se trata de serviços iguais. No entanto, a distinção ocorre que, o seguro é oferecido por uma seguradora e oferece um valor aos beneficiários envolvidos. Em alguns casos, a 
família terá que escolher uma funerária e após o sepultamento terá um reembolso do valor do funeral, ou então, terá que apanhar uma parte do prêmio para realizar o funeral. Contudo, o plano funeral pode ser tanto individual quanto familiar e a funerária responsabiliza-se por toda a parte burocrática do funeral, desde a documentação à realização do serviço em si (Primaveras, 2020).

\subsection{Objetivo do estudo}

Este estudo procura averiguar como o indivíduo identifica a necessidade ou não de adquirir um plano funeral, ou seja, quais são os estímulos, as experiências e preferências desenvolvidas durante este processo de compra. Mas também, abordando como as pessoas estão reagindo ao número de óbitos no país, por causa da pandemia. Do mesmo modo, identificando quais são os conhecimentos da população sobre um plano funerário e um seguro de vida a fim de identificar o motivo pelo qual o corpo social conhece mais um seguro de vida a um plano funeral e apontar também possíveis oportunidades para 0 mercado funerário traçar novas estratégias.

\subsection{Delimitação e foco do estudo}

Este trabalho, produzido no segundo semestre de 2021, restringe-se a indivíduos residentes do Rio de Janeiro que estejam entre a faixa etária de 31 a 63 anos, homens e mulheres. Além disso, a monografia abordará o comportamento do consumidor diante ao plano funeral, isto é, buscando compreender as classes sociais, os estilos de vida e o diferente comportamento dos indivíduos que adquirem ou não o plano funeral.

\subsection{Relevância do estudo}

As informações desenvolvidas por este trabalho têm capacidade para manifestar às empresas do ramo, por meio da análise do entendimento - sobre os planos funerários - dos potenciais clientes, delinear estratégias de comunicação e comercialização para atrair esse público e preservar os clientes já existentes. Ademais, as investigações elaboradas pela monografia podem cooperar como um informativo, para o grupo que não conhece ou nunca aprofundou no tema, mostrando a relevância de um plano funerário, com seus aspectos positivos e negativos. 
Os conceitos e teorias apresentadas ao longo da pesquisa poderão servir como embasamento para que novas ideias, no ramo funerário, possam surgir, tornando este mercado mais conhecido e valorizado no país. Além disso, os efeitos alcançados ainda poderão ser importantes para pesquisadores sobre 0 tema, estudantes e possíveis empreendedores da área. 


\section{Referencial Teórico}

Neste capítulo serão abordados temas pertinentes ao desenvolvimento da pesquisa. Fragmentados em duas partes, discorrendo, respectivamente: a compreensão completa do processo de decisão de compra dos clientes, abordando todo seu processo de experiência, de acordo com renomados autores, Kotler e Keller (2012) e Solomon (2016). Ademais, entendimento a fundo quem são os consumidores desse serviço, suas motivações e influências, no entendimento de Kotler e Keller (2012).

\subsection{Processo de decisão de compra}

Para compreender a complexidade e a incerteza do serviço com os clientes foram selecionados dois modelos de processo de decisão de compra, desenvolvido por diferentes autores, Kotler e Keller (2012) e Solomon (2016) a fim de apresentar suas diferenças, mas também suas complementações para a sustentação da teoria.

\subsubsection{Modelo de etapas}

Segundo Kotler e Keller (2012), este processo enfrentado pelo consumidor é dividido em um modelo de cinco fases, a qual consiste no(a): reconhecimento do problema, busca de informações, avaliação de alternativas, decisão de compra e comportamento pós-compra. No entanto, essas etapas não são seguidas, necessariamente, na mesma ordem, podendo variar devido ao conhecimento ou não da marca, do produto e/ou serviço. Por exemplo, ao adquirir um produto rotineiro de uma marca que já usa, o consumidor passará diretamente para a etapa da decisão de compra. Por outro lado, quando é um produto e/ou serviço totalmente diferente e fora do habitual, como um plano funerário, o consumidor pode passar por todas as etapas, conforme a figura 1 , para reconhecer a necessidade de compra do serviço. 


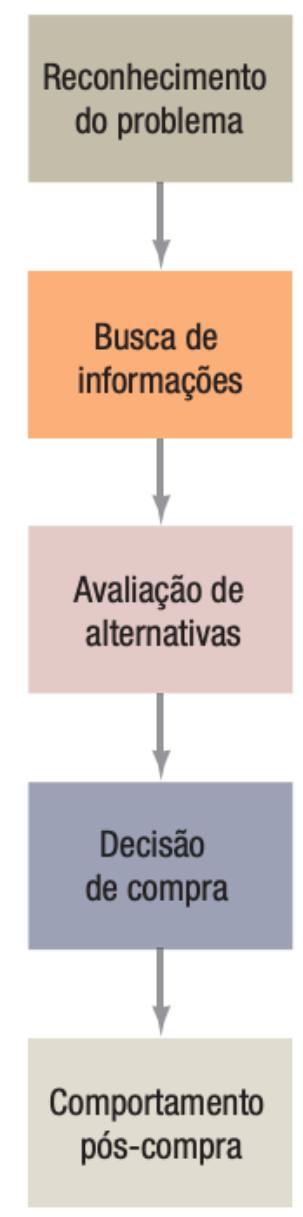

Figura 1: Modelo das cinco etapas do processo de compra do consumidor. Fonte: Administração de Marketing - Kotler e Keller (2012). p.179

A primeira etapa corresponde à identificação de um problema ou necessidade do indivíduo, que pode ser gerado por estímulos internos ou externos e que a solução pode ser encontrada em forma de um produto ou serviço. Normalmente, o estímulo interno é ocasionado por impulso em situações de necessidades básicas humanas, como segurança, fome e sede. Por outro lado, o estímulo externo é provocado, basicamente, por influências sejam elas de pessoas próximas, meios de comunicação ou por uma pessoa que tenha autoridade no assunto (Kotler e Keller, 2012). Através da identificação desses estímulos é possível elaborar estratégias usando tanto o estímulo interno quanto o externo, por exemplo, com a necessidade do comprador de ter segurança (estímulo interno) meio à pandemia e, dessa forma, projetar influência sobre o mesmo em adquirir um plano funerário (estímulo externo), pois o trará segurança nesse momento de instabilidade e também futuramente. 
A partir do momento em que os estímulos são identificados, inicia-se a fase da busca de informações. Esse processo pode ser tanto uma busca interna com suas experiências anteriores quanto com busca externa com opinião externa de pessoas, como vendedores, meios de comunicação e/ou familiares. Isto é, o consumidor procura diversas fontes de informação para adquirir um produto e/ou serviço, dentre as principais são os pessoais, comerciais, públicas experimentais. Porém, apesar da informação ser, em sua maioria, recebida por fontes comerciais, a que se torna decisiva para o consumidor são as fontes públicas ou pessoais. Além disso, Kotler e Keller (2012), ainda identificaram que há dois níveis de interesse do consumidor, onde um está mais disposto a receber informações sobre um produto e no outro nível o mesmo busca informações com familiares e internet para conhecer mais o produto e/ou serviço. Compreendendo a importância de encontrar os atributos que auxiliam a tomada de decisão do consumidor, a empresa de um plano funerário, precisa identificar a hierarquia de atributos. Visto que, essa identificação poderá apontar o segmento de clientes e também outras empresas que estão no conjunto de escolha do consumidor.

Neste estágio de avaliação de alternativas, os consumidores utilizam as informações obtidas para analisar as empresas disponíveis. No entanto, o comportamento do consumidor durante o período de avaliação da marca pode ser diferente. Alguns usam o raciocínio lógico, enquanto outros confiam na intuição e na emoção para tomar decisões de compra. Outros tomam suas próprias decisões e alguns preferem a opinião de pessoas próximas ou mesmo de vendedores. Cada produto ou serviço, mesmo que seja desenvolvido para assistir necessidades específicas, será implementado de forma diferenciada, sempre com base em seu conjunto de atributos. Os consumidores estão preocupados com os atributos que os proporcionam os benefícios desejados, que variam conforme o produto e/ou serviço. Os esforços dos consumidores na avaliação de alternativas dependerão muito do número de marcas, das diferenças entre as marcas e da importância e complexidade do produto ou serviço na visão do consumidor. Tal comportamento está associado às crenças e atitudes do consumidor adquiridas por suas experiências com produtos e/ou serviços iguais ou semelhantes (Kotler e Keller, 2012). Dado que, o pensamento e avaliação pode ser tanto positivo quanto negativo, uma empresa de plano funerário, por exemplo, poderia empregar estratégias para desvincular a ideia negativa de se ter um plano e, também, para incentivar a utilidade do serviço, por meio do reposicionamento psicológico - ação de modificar as crenças sobre 
a marca - e mudança do ideal do comprador, que consiste em criar meios para alterar o nível de exigência de alguns atributos estipulados pelo consumidor.

No momento em que o consumidor estabelece a intenção de compra, de acordo com suas preferências entre as marcas, desenvolvida na etapa da avaliação de alternativas. Com base nisso, o mesmo pode enfrentar mais cinco subdecisões, como a decisão por marca, quantidade, ocasião e por forma de pagamento. Ou seja, esta etapa não necessariamente será uma compra totalmente decidida, dependendo de como for realizada a subdecisão pelo consumidor, a marca do produto e/ou serviço pode ser alterada, adiada ou cancelada. O motivo pelo qual isso sucede, é devido aos fatores de interferência entre a intenção de compra e a decisão de compra, que são a atitude de outros e os fatores situacionais imprevistos, conforme a figura 2. Em relação à atitude de outros, expressa que, à medida que o negativismo de outra pessoa que seja próxima do consumidor, maior será a probabilidade de o mesmo ajustar sua intenção de compra e vice-versa. Em contrapartida, os fatores situacionais imprevistos podem acontecer a qualquer momento e mudar a intenção de compra do consumidor. Entretanto, esse fato acontece devido a interferência do risco percebido. Por exemplo, o cliente estava planejando adquirir um plano funeral para sua família, porém, ocorreu algo imprevisível e foi dispensado de seu emprego. Dessa forma, alguma outra compra pode ser mais essencial, ou então, praticar a contenção gastos. A fim de, converter essa situação, as empresas funerárias deverão identificar os fatores que geram essas impressões de risco no consumidor e criar embasamento para que as pessoas percebam que o plano funerário é um serviço necessário para a vida delas. 


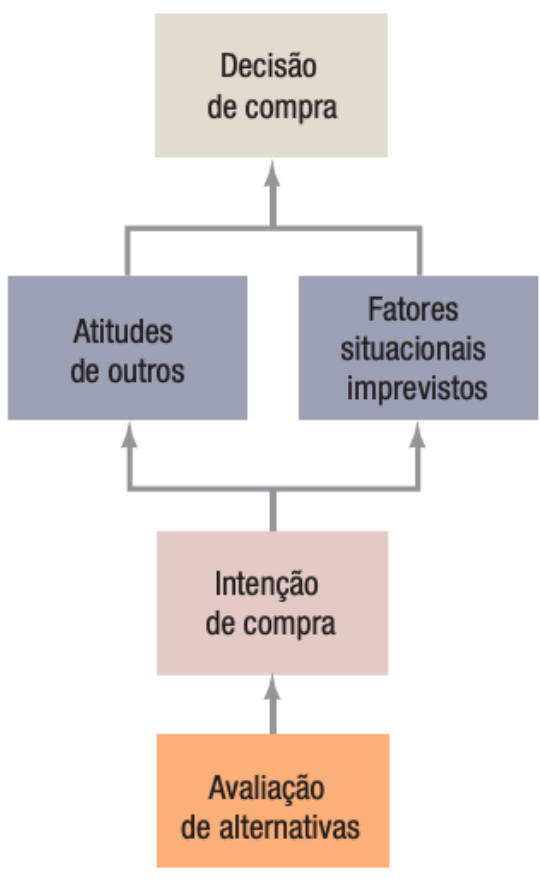

Figura 2: Etapas entre a avaliação de alternativas e a decisão de compra. Fonte: Administração de Marketing - Kotler e Keller (2012). p.184

Posteriormente à realização da aquisição do produto e/ou serviço, inicia-se fase do comportamento pós-compra do consumidor. Diante disso, é veemente importante o acompanhamento do nível de satisfação dos clientes e também de seus comportamentos após a compra do produto e/ou serviço. Visto que, tanto a satisfação quanto a insatisfação provocam grandes repercussões para a empresa, dado que, se as expectativas do cliente forem atendidas e/ou superadas, há uma alta possibilidade de o consumidor comprar novamente e de realizar indicações favoráveis para outras pessoas sobre a marca. No entanto, quando as expectativas produto e/ou serviço e desempenho não são atendidos os consumidores se sentem desiludidos com a marca, ocasionando comentários negativos para grupos próximos, descrédito pela qualidade em uma outra compra, preferindo analisar outra empresa que oferece o mesmo produto e/ou serviço, e também, procurar pelo direito do consumidor com um advogado. Para construir uma boa imagem, a empresa deve investir no atendimento pós-venda, mostrando disponibilidade e velocidade em possíveis adversidades, estando à disposição para sugestões de melhorias dos consumidores. 


\subsubsection{As três categorias de tomada de decisão do consumidor}

De acordo com Solomon (2016), cada decisão de compra que o consumidor realiza é uma resposta a uma dificuldade identificada pelo mesmo. Entretanto, é preciso entender que, cada necessidade é distinta uma da outra, logo, os seus esforços também são divergentes. Conforme Solomon (2016, p. 38) "é óbvio que é difícil utilizar uma explicação padronizada para as complexidades do comportamento do consumidor". Dessa forma, é possível observar que a tomada de decisão é uma sucessão de estratégias denominado por pensamento construtivo, onde o esforço básico é analisado para realizar uma escolha e, em seguida, o esforço cognitivo - escolha racional - é adaptado para tomar uma determinada decisão. Além disso, Solomon (2016), apresenta a tomada de decisão do consumidor como três recipientes, embora sejam distintos, ambos são correspondentes. Logo, o consumidor toma decisões respaldado em cada um desses recipientes descritos como cognitivo, habitual e afetivo (Figura 3).

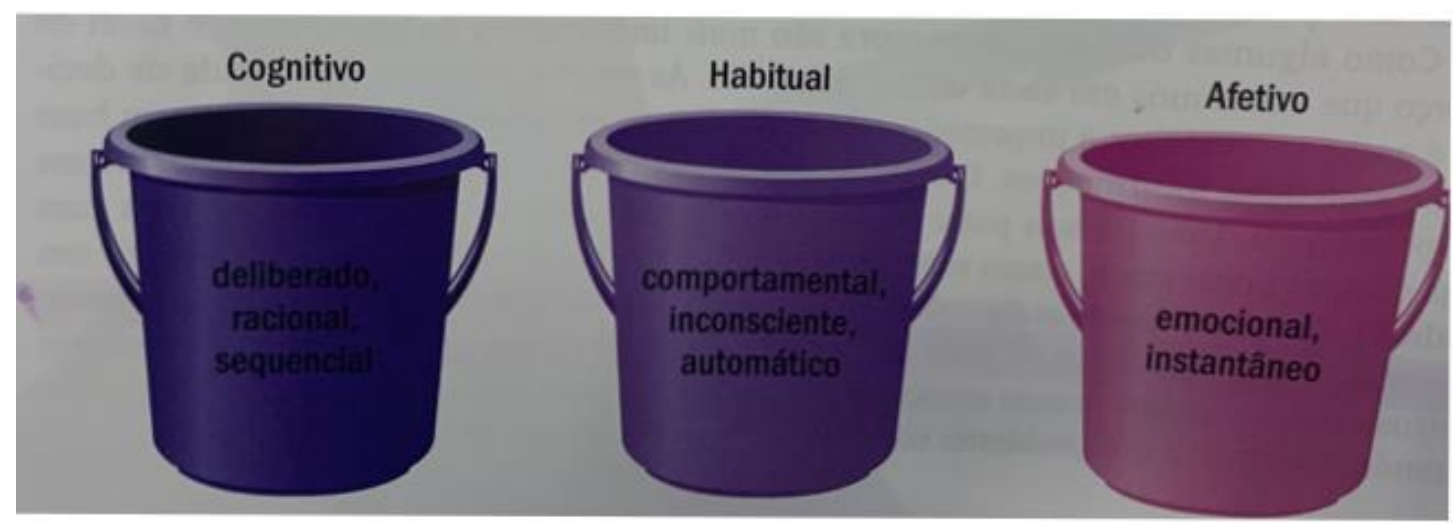

Figura 3: Os três recipientes da tomada de decisão do consumidor. Fonte: O comportamento do consumidor - Solomon (2016). p.38

No entanto, o nível de envolvimento do consumidor tem grande impacto para sua tomada de decisão, visto que, os consumidores são capazes de passar por situações de escolhas idênticas e, ainda sim, apresentar distintas concepções, isto acontece por causa da dissemelhança do nível de envolvimento de cada consumidor e, também dos diferentes fatores que geram envolvimento, como pessoais, de estímulo e situacionais. Além disso, ao passo que o envolvimento do consumidor se intensifica, o mesmo se interessa mais em conhecer o produto e/ou serviço e despender mais tempo nessa pesquisa. Aliás, 
há um envolvimento maior quando o produto e/ou serviço requer um investimento financeiro elevado, diferentemente com produtos e/ou serviços mais baratos. Apesar disso, é interessante salientar que, os consumidores são diferentes uns dos outros e, com isso, seus envolvimentos também são diferentes, podendo ser alto ou baixo, independentemente do valor do produto e/ou serviço. A figura 4 demonstra que tomada de decisão cognitiva e emocional tendem a ter um maior grau de envolvimento a uma decisão habitual, que é realizada de forma mais automática e inconsciente.

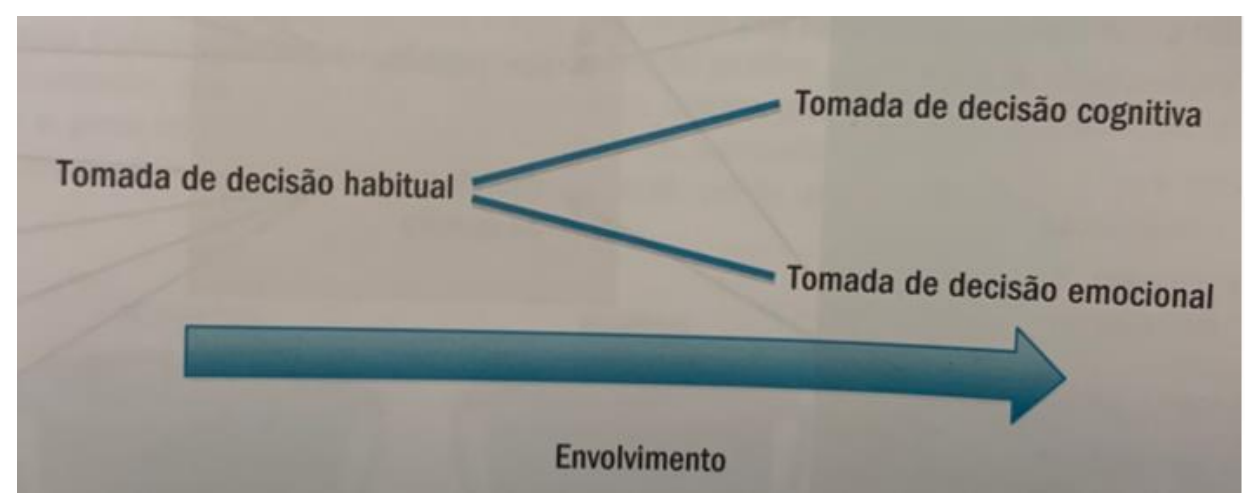

Figura 4: Envolvimento e tomada de decisão.

Fonte: O comportamento do consumidor - Solomon (2016). p.40

\subsubsection{Cognitiva}

A abordagem da tomada de decisão cognitiva baseia-se em perspectivas racionais do consumidor, com planejamento e análises profundas dos prós e contra de cada opção a fim de efetuar uma compra aceitável (Solomon, 2016). As etapas enfrentadas pelo consumidor são similares às elaboradas por Kotler e Keller (2012), como: reconhecimento do problema; busca de informações, avaliação de alternativas; e escolha do produto.

Entretanto para Solomon (2016), o reconhecimento do problema pode aparecer e variar de dois modos, o estado real e o estado ideal (Figura 5). 0 primeiro consiste na identificação de uma necessidade atípica. Em contrapartida, o estado ideal corresponde ao reconhecimento da oportunidade, ou seja, a vontade do consumidor em adquirir algo sem necessariamente ter algum problema com o que ele tem atualmente. O estado varia de acordo com a cultura, subcultura, grupos de referência, tendências e estilo de vida que cada consumidor dispõe no momento. 


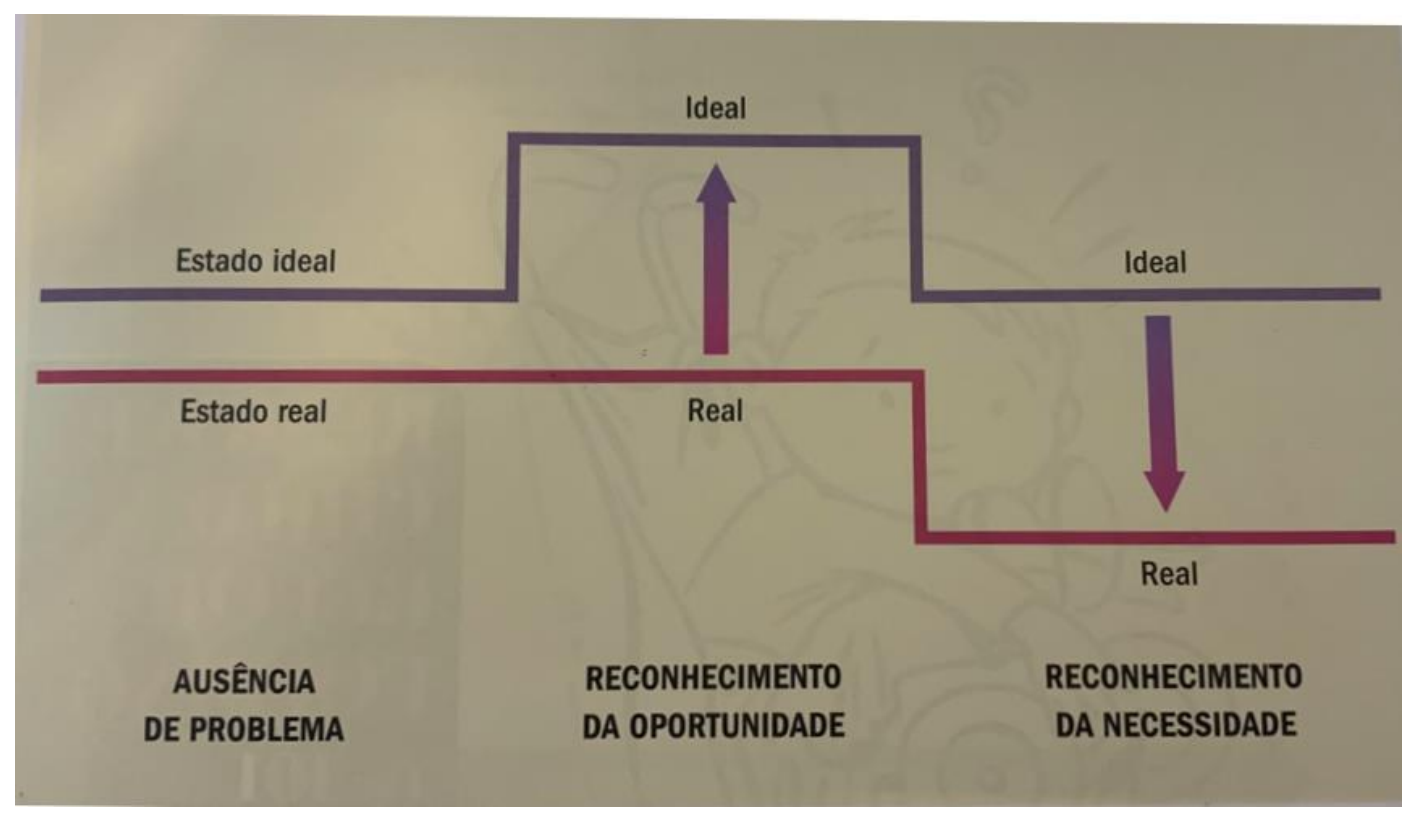

Figura 5: Mudanças no estado real e ideal.

Fonte: O comportamento do consumidor - Solomon (2016). p.49

O consumidor busca informações para criar um embasamento para fazer uma escolha satisfatória seja de um produto ou serviço. Há três tipos de busca de informação: a busca interna, externa e contínua. A primeira a ser cumprida é busca interna, onde o consumidor irá resgatar na memória as experiências passadas de compra. Se a experiência for alta e satisfatória, menor será a busca por informações externas. No entanto, quando a busca interna não é suficiente, o consumidor busca por informações externas, ou seja, coleta opiniões de pessoas próximas. Além disso, existe a busca contínua, que é uma atividade de busca que não tem relação com um problema, isto é, a pessoa só busca informação porque quer se manter ciente (Solomon, 2016).

A avaliação de alternativas fundamenta-se na vontade do consumidor em satisfazer suas necessidades pessoais. A necessidade de afiliação compreende a vontade do consumidor em estar na presença de outras pessoas, em grupos. Por outro lado, necessidade de poder é a qual o consumidor possui a sensação controle e autoridade. E, por último, a necessidade de singularidade que é a aspiração de reconhecer a identidade individual do consumidor (Solomon, 2016).

O momento da escolha do produto envolve as ações da compra, ou seja, a forma de venda, pagamento e a marca a ser selecionada. Além disso, são efetuadas análises de todos os atributos, geralmente, em produtos e/ou serviços de alto investimento pelos consumidores. Por outro lado, existem dois critérios compensatórios de seleção de marcas, o aditivo simples e o aditivo ponderado. 
No primeiro, o consumidor analisa todos os atributos do produto e/ou serviço, pontua cada atributo e, por fim, soma as pontuações de todos os atributos e, a seguir, seleciona o produto com a pontuação mais alta. No segundo critério, cada atributo relevante na avaliação do consumidor tem um peso. O peso é considerado junto com a pontuação de cada atributo, e finalmente, é selecionado o produto com a melhor soma dos pontos ponderados (Solomon, 2016).

\subsubsection{Habitual}

Essa tomada de decisão está entre a cognitiva e a afetiva, ou seja, existe pouco envolvimento emocional e baixo nível de pensamento racional e lógico. Dessa forma, o comportamento de decisão de compra, praticamente, é efetuado sem nenhum planejamento e baseado na impulsividade do consumidor. Apesar de serem compras sem o esforço consciente, normalmente, são compras eficientes. No entanto, há duas formas de impactar o consumidor a tomar essas decisões precipitadas e rotineiras. A primeira consiste na pré-ativação (priming) onde o produto e/ou serviço estão alocados em pontos estratégicos para despertar a necessidade, a qual é gerada inconscientemente - abaixo do limiar de percepção consciente. Por outro lado, a segunda forma é baseada no "empurrãozinho" (nudging), isto é, à medida que alterações no local do consumidor acontecem, os comportamentos também são modificados. Embora a tomada de decisão cognitiva destaque ideias pesquisa mais profundas, em muitos casos, os consumidores raramente fazem pesquisas. Com isso, eles recorrem aos atalhos mentais a fim de facilitar o processo de tomada de decisão. Como resultado, os consumidores têm certas crenças que podem ou não afetar as decisões de compra. Por exemplo, a qualidade está relacionada ao preço (quanto mais alto o preço, maior a qualidade), marcas conhecidas trazem mais certeza à qualidade e ao país de origem do produto. (Solomon, 2016).

\subsubsection{Afetiva}

A tomada de decisão afetiva é uma escolha baseada na mudança dos estados emocionais do consumidor, ou então, por meio de associações do consumidor por meio de produtos com reações emocionais, gerando uma ação de compra sem a análise de opções, sendo uma decisão, única e exclusivamente, emocional. O consumidor pode expor tanto um afeto positivo quanto negativo por um produto e/ou serviço. Dessa forma, quando um cliente 
se sente seguro com uma marca específica, o mesmo torna-se disposto a gastar um valor mais alto por apresentar confiança. No entanto, quando o cliente é apresentado a uma situação que o desperte ao sentimento de aversão à uma situação, o mesmo busca adquirir, instantaneamente, um produto e/ou serviço para evitar que aconteça novamente ou venha acontecer por uma situação desconfortante (Solomon, 2016). Ou seja, o plano funerário pode atuar nas duas esferas - positiva e negativa - praticando a sensação de ser uma empresa que transmita a segurança, o acolhimento do consumidor no momento mais doloroso e também mostrando situações desconfortantes que podem acontecer por não se respaldar com um plano funerário.

\subsection{Análise de mercados consumidores}

Com o intuito de compreender a fundo quem são os consumidores de planos funerários, juntamente com suas motivações, influências e necessidades é preciso captar além do modo de como compram, mas também dos fatores que os induzem. Para Kotler e Keller (2012), os aspectos que interferem nas preferências dos consumidores estão entre os culturais, sociais, pessoais e psicológicos.

\subsubsection{Fatores culturais}

A cultura e a influência do local em que a pessoa vive, a de familiares e de amigos próximos é extremamente decisivo para a construção de valores de um indivíduo. Entretanto, a cultura é um fator mais amplo comparado a uma subcultura, a qual abrange a identificação de uma pessoa com um grupo mais específico, por exemplo, de acordo com sua nacionalidade, religião, grupo racial e região estadual. Além disso, as classes sociais são representações e divisões de uma sociedade, onde existem grupos que possuem hábitos, preferências, rendas familiares e princípios semelhantes (Kotler e Keller, 2012).

\subsubsection{Fatores sociais}

Segundo Kotler e Keller (2012), os fatores sociais são fundamentados em grupos de referência, família, papéis sociais e status. No entanto, os grupos de referência são compostos por interferências diretas e indiretas. Dessa forma, os grupos de ação direta baseiam-se em familiares e amigos (grupos primários), ou seja, pessoas próximas com crenças e valores próximos e também presente no 
cotidiano do indivíduo. Por outro lado, os grupos de ação indireta estão relacionados às subculturas, isto é, a grupos relevantes para o indivíduo, porém é mais distante e formal - grupo secundário - como profissionais e parentes, os quais não têm uma ligação tão próxima quanto os grupos primários. Em sua maioria, o indivíduo é influenciado pelo grupo de referência que está próximo à sua realidade. Contudo, o consumidor pode ser influenciado por grupos que ele não tem proximidade, como a grupos que ele não participa, mas tem o desejo de um dia participar - grupos aspiracionais. Em contrapartida, existem os grupos dissociativos, onde o contato é totalmente rejeitado. Além disso, têm os líderes de opinião, que são pessoas influentes no assunto e que transmitem segurança e verdade para o indivíduo.

Sob outra perspectiva, a família estabelece o grupo de referência primário mais persuasivo e, por esse motivo, verificou-se a existência de dois tipos de famílias. A família por orientação, que envolve os pais e irmãos do comprador. A segunda seria por procriação, abrangendo o cônjuge e os filhos, a qual gera mais impacto, por ser um convívio mais direto, visto que, em produtos e/ou serviços que possuem valores mais elevados, o casal toma a decisão juntos de adquirir ou não. Além de que, os filhos estão mais atentos às novidades do mercado, podendo gerar uma motivação de compra para comida e lazer, por exemplo. No que se refere aos grupos de referência, as pessoas participam de inúmeros grupos e a todo momento diversas informações são dispersadas entre os participantes, envolvendo certas condutas de desempenho. Com isso, o papel e o status de uma pessoa, estão intimamente relacionados, visto que, o papel é o comportamento projetado ao indivíduo e o status é a sua posição dentro da estrutura do grupo.

\subsubsection{Fatores pessoais}

Os fatores pessoais incluem idade e estágio do ciclo de vida, ocupação, condições econômicas, estilo de vida, personalidade e autoimagem. Em todas as fases da vida as aspirações e as necessidades se modificam. É preciso entender a necessidade de cada pessoa em particular, como os jovens, recém-casados, casais com ou sem filhos, são necessários produtos diferentes em cada fase e os hábitos de consumo mudam de acordo com cada momento da vida. A vida profissional também impacta e estabelece hábitos de consumo e produtos diferentes, bem como estilos de vida. Pessoas com maior poder aquisitivo não irão para o mesmo lugar que a classe média ou casais com filhos, os requisitos 
são distintos. As pessoas se relacionam com muito mais facilidade a empresas que estão próximas com a personalidade do consumidor e também ao seu estilo de vida - a forma como a pessoa molda e decide viver sua vida (Kotler e Keller, 2012).

\subsubsection{Fatores psicológicos}

No que se refere aos fatores psicológicos, estes envolvem motivação, percepção, aprendizagem e memória. Todos os componentes afetam a decisão de compra do consumidor. A motivação é baseada no estado intrínseco, que leva ao comportamento direcionado para objetivos. Um princípio que esclarece corretamente esse fator, é a hierarquia de necessidades de Maslow. Conforme as pessoas vão satisfazendo suas necessidades mais básicas, elas vão mudando seus interesses e necessidades para outras mais complexas, como mostra a figura 6.

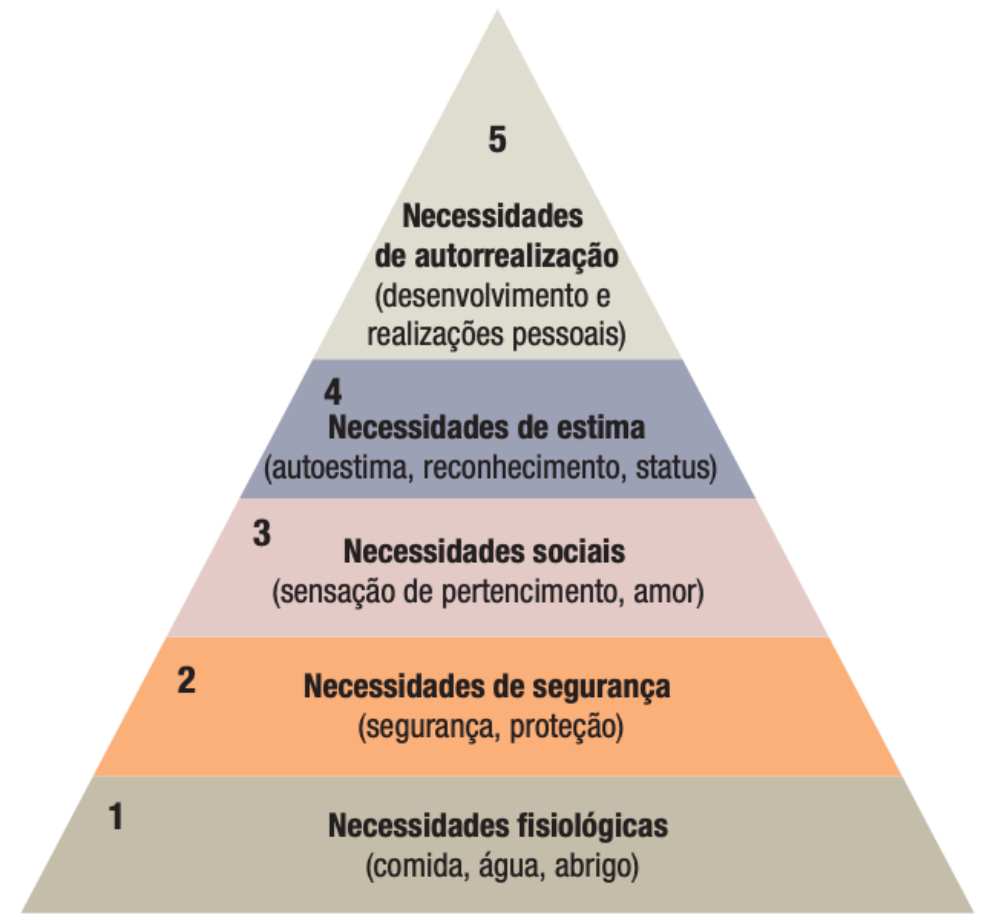

Figura 6: Pirâmide de hierarquia das necessidades de Maslow.

Fonte: Administração de Marketing - Kotler e Keller (2012). p.174

Qualquer pessoa pode estar diante de um mesmo estímulo, mas cada uma delas irá ter uma percepção e comportamento diferente dessa informação. 
Esse acontecimento deriva por causa de três motivos: a atenção seletiva, distorção seletiva e retenção seletiva. A todo momento as pessoas são expostas a inúmeras propagandas ou informações. Com isso, as pessoas selecionam essas informações inconscientemente e focam nos estímulos que se correlata com uma necessidade individual e também à estímulos totalmente inesperados (atenção seletiva). Ademais as pessoas filtrarem esses estímulos, as informações que são recebidas, são interpretadas de formas diferentes por cada indivíduo. Dado que, essa provocação vai ser distorcida para se adequar às crenças e expectativas pessoais (distorção seletiva). Dessa forma, as pessoas só retêm as informações que mais se aproximam de suas atitudes e crenças, as demais são esquecidas, esse processo é chamado de retenção seletiva (Kotler e Keller,2012)

A partir do momento em que uma pessoa passa por uma experiência seja positiva ou negativa, a mesma altera seu comportamento e percepção sobre uma marca. Normalmente, a aprendizagem surge através de estímulos, impulsos, sinas, respostas e reforços. De acordo com o nível de satisfação da experiência do consumidor, sua resposta pode variar. Por exemplo, uma pessoa contrata um serviço funerário e ao final possui uma experiência satisfatória, logo, sua resposta será forte e positivamente reforçada. Com isso, irá generalizar que outros serviços e produtos da empresa são de qualidade e, consequentemente, irá transferir fidelidade à marca e ao serviço funerário de modo geral. Mas, é necessário estar a atento, visto que, o oposto também pode ocorrer (Kotler e Keller, 2012).

Uma vez que, o consumidor passa por uma experiência ou recebe uma informação nova, esse acontecimento é armazenado em sua memória, podendo ser de curto ou longo prazo. Além de guardar esses estímulos é importante compreender que, as informações podem ser resgatadas a qualquer momento quando o consumidor receber a provocação necessária. No entanto, essas informações não são recuperadas em sua integralidade, por isso, as marcas têm que estar sempre reforçando a importância e a qualidade de seus produtos e/ou serviços para o consumidor a fim de convencer e mudar seu pensamento em caso de uma memória negativa (Kotler e Keller,2012). 


\section{Métodos e procedimentos de coleta e de análise de dados do estudo}

Neste capítulo serão apresentadas as etapas que foram desempenhadas para a coleta de dados da pesquisa em estudo. Está dividido em quatro partes, respectivamente: etapas de coleta de dados; fontes de informação selecionadas e os procedimentos de coleta de dados utilizados no estudo; formas de tratamento e análise dos dados coletados; e as limitações do estudo.

\subsection{Etapas de coleta de dados}

As etapas de coleta de dados desta pesquisa, divide-se em duas partes, dois grupos de entrevistas com participantes de perfil distinto. Vale ressaltar que, ambas etapas consistem em uma pesquisa exploratória qualitativa, visando compreender os pensamentos do público que possui o plano funerário, por um lado, e o grupo que não possui esse serviço no Rio de Janeiro, por outro lado. Além disso, procedimento oferece a possibilidade de alcançar as respostas profundas para questões particulares que envolvem a razão da escolha de possuir ou não um plano funerário, desvendando os aspectos subjetivos da experiência humana no processo de compra deste serviço. Vale ressaltar que, os roteiros de todas as etapas estão disponíveis no anexo 1 desta pesquisa.

\subsection{Fontes de informação selecionadas e os procedimentos de coleta de dados utilizados no estudo}

Em relação à seleção dos participantes foi dado a preferência na escolha segundo o critério de amostragem por acessibilidade ou conveniência, isto é, uma amostra de pessoas que seja acessível e prontamente disponível para participar da entrevista, sem nenhuma seleção por critério estatístico. Além disso, que estivessem de acordo com o problema em estudo e desde que os participantes tivessem uma mínima vivência com o tema a ser discutido, possibilitando uma troca de informações de qualidade (Ochoa, 2015). Dessa forma, foram selecionados os participantes que estivessem na faixa etária entre 31 a 63 anos de idade, aproximadamente, homens e mulheres. Ademais a coleta de dados foi realizada via conversas por áudio via WhatsApp, com 10 pessoas 
ao todo, sendo 5 pessoas que possuem o plano funerário, 5 pessoas que não possuem o plano funerário.

Anteriormente foi realizado um planejamento onde os participantes foram convidados com dez dias de antecedência, fornecendo aos entrevistados o mínimo de informação possível, apenas o essencial, para que não houvesse nenhuma preparação prévia, visto que o objetivo era entender os seus questionamentos, as interações e experiências com o assunto e motivos de possuírem ou não o plano. A seleção dos entrevistados foi realizada de forma totalmente discreta para que os mesmos não desconfiassem que o assunto principal seria plano funerário. Ademais, foram abordados os mesmos questionamentos para ambos os grupos. As entrevistas individuais foram bem aprofundadas, devido à elaboração de um roteiro semiestruturado (Anexo 1) que ofereceu liberdade para alterar e levantar assuntos que surgiram no momento das entrevistas.

\subsection{Formas de tratamento e análise dos dados coletados}

Após a coleta de informações através das entrevistas individuais, foi realizada analise de conteúdo das falas dos entrevistados. Foram transcritos alguns trechos que foram analisados qualitativamente a fim de estruturar as respostas de acordo com cada pergunta realizada. Além disso, foi realizado um agrupamento das respostas para obter melhor interpretação dos resultados, proporcionando uma visão das semelhanças e das diferenças entre as respostas, relacionando também com o referencial teórico da pesquisa (Bauer e Gaskell, 2008).

\subsection{Limitações do Estudo}

Todas as entrevistas foram realizadas de forma remota, o que pode gerar uma alteração na dinâmica, pelo fato de as conversas terem sido realizadas por áudio. No entanto, esta eventualidade não apresenta interferência quanto a eficiência da pesquisa, visto que, os resultados alcançados têm o objetivo de informar e mensurar as questões expostas ao longo do estudo. 


\section{Apresentação e análise dos resultados}

Este capítulo apresentará os dados coletados no decorrer das entrevistas individuais, como também as ponderações e conclusões sobre os temas abordados.

\subsection{Descrição do perfil dos entrevistados}

O grupo reunido para a realização da pesquisa foi elaborado com 10 entrevistados, que se denominam como 6 pessoas do sexo feminino e 4 pessoas do sexo masculino, com faixa etária entre 31 a 63 anos do estado do Rio de Janeiro, como demostra o quadro abaixo (Tabela 1), juntamente com a respectiva localidade dos entrevistados. Vale ressaltar que, a identificação dos entrevistados nas pesquisas não foi mencionada para preservar seus dados e imagem.

\begin{tabular}{|c|c|c|c|}
\hline NOME & SEXO & IDADE & LOCALIDADE \\
\hline Entrevistado 1 & Feminino & 63 & Nova Iguaçu \\
\hline Entrevistado 2 & Feminino & 49 & Barra da Tijuca \\
\hline Entrevistado 3 & Masculino & 62 & Nova Friburgo \\
\hline Entrevistado 4 & Feminino & 31 & Nova Iguaçu \\
\hline Entrevistado 5 & Feminino & 33 & Jacarepaguá \\
\hline Entrevistado 6 & Masculino & 47 & Queimados \\
\hline Entrevistado 7 & Feminino & 43 & Austin \\
\hline Entrevistado 8 & Feminino & 31 & Queimados \\
\hline Entrevistado 9 & Masculino & 39 & Queimados \\
\hline Entrevistado 10 & Masculino & 60 & Bangu \\
\hline
\end{tabular}

Tabela 1: Perfil dos participantes entrevistados.

Fonte: Da autora 


\subsection{Análise dos resultados do grupo que não possui plano funerário}

A entrevista praticada com os entrevistados foi efetuada com seis perguntas principais, mas por tratar-se de um roteiro semiestruturado, tiveram algumas perguntas diferentes além das principais para obter respostas mais profundas. Contudo, vale ressaltar que, o foco não foi desviado com as perguntas paralelas às principais.

Com o intuito de compreender o que o número de óbitos no país gerou de sentimentos e sensações nas pessoas durante o período de pandemia, essa questão foi abordada nas entrevistas. Com isso, foi observado que dos cinco entrevistados, três pessoas enxergaram essa situação no país como algo transformador, evolutivo para o ser o humano, mesmo com toda a insegurança e preocupação com o número de óbitos. Como um entrevistado sinalizou: "Infelizmente, esse momento, essa pandemia veio para nos ajudar a evoluir mais como pessoa, como ser humano". Por outro lado, os outros dois entrevistados citaram que foi um período de muito medo e pavor, bem como, o comentário de um deles: "Eu tive medo da perda, medo de ver as pessoas morrendo".

Tais informações demonstram que o argumento, de Kotler e Keller (2012), é preciso quando se trata sobre a primeira fase do modelo das cinco etapas, a identificação de um problema ou necessidade. Visto que, independente da opinião dos entrevistados, ambos citaram a preocupação com o número de mortes, o qual gerou estímulos externos, devido aos meios de comunicação, e estímulos internos de necessidade básicas humanas, como de segurança. Aos que trataram a morte como algo natural do ser humano, é mais presumível que em algum momento esse grupo procure um plano para se preparar. Por outro lado, os que têm mais receio da morte, é capaz que haja uma resistência na contratação deste serviço. Para ambos os casos, é fundamental que as empresas estejam em constante contato com esse público, para prestar o devido suporte de explicações sobre o serviço, de sua importância e para tornar fatores estimulantes de compra.

$\mathrm{Na}$ questão seguinte, foi indagada a pergunta sobre os cuidados que seriam importantes para se pensar quando alguém próximo da família falece. Desse modo, todos os entrevistados abordaram, primeiramente, assuntos emocionais do momento da perda, como a preocupação com familiares, a prestação de solidariedade e a sensação de estar perdido. Posteriormente, citaram os trâmites mais burocráticos, como 0 ponto financeiro, as 
documentações e o contato com uma funerária. Interessantemente, um entrevistado citou o plano funerário como um facilitador dos assuntos burocráticos, pode-se observar na fala: "Para quem não tem um plano funerário fica até mais burocrático, para quem já tem, não sei como funciona, mas acredito que fica mais fácil de comunicar ao plano o que aconteceu". Além disso, outra pessoa citou uma experiência familiar que possuía o plano e que, por isso, tornou o processo mais tranquilo, como o mesmo expõe:" Quando a minha vó faleceu, foi um momento que a gente ficou sem chão, mas graças a Deus, pelo fato dela ter um plano, a funerária foi acionada, onde ela foi cuidada com muito carinho".

Analisando-se os dados citados na questão dos cuidados, torna-se evidente que, os entrevistados que citaram o plano funerário como um simplificador, mesmo não possuindo, estão reconhecendo um problema de forma inconsiente. Visto que, ambos reconhecem a oportunidade, no entanto, não reconhecem a necessidade de adquirir um plano funerário. Apesar do pouco conhecimento e com experiências de familiares, no momento, ambos não consideram algo essencial (Solomon, 2016). Quanto a preocupação dos entrevistados em prestar apoio aos familiares antes de prosseguir com a parte burocrática, é de suma importância que as empresas funerárias entendam esse comportamento. Dado que, é uma oportunidade para as mesmas reforçarem a ideia de poupar as famílias de todos os trâmites funerários e permitir que essas famílias possam ter mais tranquilidade num momento de perda.

Em sequência, foi perguntado sobre a experiência dos entrevistados quanto aos serviços funerários desde a contratação até o sepultamento. Duas pessoas citaram que nunca tratou um funeral diretamente, mas que lembram de experiências de pessoas próximas. A primeira, ajudou uma conhecida financeiramente com o funeral, pois foi algo inesperado e que não tinha se planejado. A outra entrevistada relatou que um parente tinha o plano e que o pai foi fazer o reconhecimento do corpo, mas que foi a única parte chocante. Os demais entrevistados tiveram experiência própria da contratação do serviço funeral, alegaram que foi uma experiência satisfatória e que buscaram as empresas através de indicação de conhecidos, como pode-se observar: "Eu recorri a uma pessoa próxima de mim que me ajudou muito com essa parte burocrática".

Ao explorar os conceitos que poderiam estar associados à vivência dos entrevistados, ficou visível que, os fatores sociais de Kotler e Keller (2012), mostra que a experiência de pessoas próximas, os induzem, direta ou 
indiretamente, a criarem opiniões a cerca dos procedimentos e necessidades que esse serviço carece. Mesmo não possuindo uma experiência própria. Sendo que, é necessário compreender além do modo como as pessoas consomem, mas também os fatores que os influem, para que as empresas consigam lidar, pois essas concepções podem ser tanto positivas, quanto negativas.

Após os questionamentos a cerca das experiências e percepções individuais sobre assuntos de falecimento, foi abordado se em algum momento eles já pensaram em ter um plano funerário. Dos cinco entrevistados, três falaram que já pensaram, no entanto, por motivos diferentes. O primeiro expressa a vontade de ter um plano, mas não possui o apoio da família, pois os demais enxergam como um agouro à família. O próximo diz pensar nos momentos difíceis, mas que depois vai se acomodando. O último revela que sempre pensou e a vontade aumentou devido a pandemia, mas devido o dia a dia, acaba dando prioridade à outras necessidades. Os outros dois, alegaram que nunca pensaram, sendo um deles disse que, recentemente, conversou com a família a respeito de plano funerário e que estão pensando na possibilidade.

Baseado nas informações sobre o interesse ou não do plano funerário, é possível observar que, ainda existe um certo tabu a respeito desse serviço e que as funerárias devem mostrar que um plano funerário é tão importante quanto, por exemplo, um plano de saúde, que apesar de diferentes, eles têm um objetivo em comum, prestar assistência. Além disso, criar campanhas estratégicas com o intuito de estar cada vez mais presente nos assuntos familiares, para que o plano seja visto como um serviço preventivo.

Com relação a como os entrevistados conseguem diferenciar um seguro de vida de um plano funerário, foi constatado que apenas dois entrevistados expuseram uma diferenciação, referindo o seguro de vida como uma indenização e uma bonificação à um familiar. Quanto ao plano funerário, discorreram que é algo mais específico ao funeral em si e uma forma de tranquilidade num momento difícil. Contudo, os outros três manifestaram não saber a diferença entre um e outro. Como os trechos destacados: "Eu tenho pouco conhecimento"; "Não consigo diferenciar não, pra mim é tudo a mesma coisa"; e "Não sei exatamente a diferença e nem quais as vantagens entre um e outro". Com isso, notou-se que há uma certa dúvida quanto a diferenciação real entre um serviço e outro. Consequentemente, as empresas funerárias devem intensificar em seus canais de comunicação o contraste entre os serviços e reforçar o diferencial de sua atividade. 
Na última pergunta, os cinco entrevistados foram questionados sobre quais aspectos acham que dificulta o processo de contratação de um plano funerário. Apenas dois entrevistados conseguiram discorrer sobre o tema. Um disse que acredita que a maioria das pessoas não pensam na morte, como o mesmo citou: "O que dificulta as pessoas realmente aceitarem ou contratarem, é essa coisa de achar que nunca vai acontecer". O outro abordou a questão da falta de prioridade para a contratação deste serviço, como revelou: "Por exemplo, eu mesmo. Eu quero fazer, tenho esse conhecimento, mas acabo dando prioridade a outras demandas". Os demais, três entrevistados, não identificaram uma dificuldade expressiva que atrapalhe a contratação, apenas a falta de interesse.

Tais comportamentos que devem ser examinados com atenção, visto que, esses relatos estão associados aos aspectos que atuam na preferência de compra, como os fatores culturais e pessoais. Quando o entrevistado relata que, existe o convencimento de que nunca vai acontecer, esse pensamento está intimamente ligado ao fator cultural, ou seja, suas crenças e valores. Em contrapartida, quando declaram que dão prioridades à outras ações e também a falta de interesse, é visível que, os fatores pessoais induzem suas decisões, por motivos de estágio de ciclo de vida ou então circunstâncias econômicas (Kotler e Keller, 2012). Por isso, a área de marketing deve estar em constante comunicação com o departamento de vendas, a fim de entender cada vez mais os comportamentos dos clientes e das pessoas que não têm interesse nos planos. Para que, consigam elaborar programas de marketing específicos para atendê-los.

\subsection{A Análise dos resultados do grupo que possui plano funerário}

Com esse grupo de cinco pessoas, também foi executada uma entrevista com seis perguntas principais, a qual contava com, praticamente, as mesmas perguntas principais do grupo que não tem o plano. $O$ roteiro semiestruturado permitiu que fosse realizada perguntas paralelas conforme a conversa individual com cada entrevistado. Vale acentuar que, os questionamentos paralelos, não interferiram no objetivo central das perguntas.

Para começar foi questionado o que o número de óbitos no país, devido a pandemia, gerou em cada um dos entrevistados. Desse modo, ambos citaram a preocupação com o número de mortes no país, mas não foi citado por nenhum entrevistado o sentimento de medo, foi mencionado a fragilidade, a tristeza, a 
preocupação, solidão e reflexão. Exemplificativamente no discurso dos entrevistados: "Uma sensação ruim de ver o desespero das pessoas, a tristeza no olhar de cada um na rua"; e "Sensação de fragilidade, tristeza e de muita reflexão da nossa vida". Além disso, um dos entrevistados, citou que um familiar faleceu devido a pandemia.

Durante a conversa com esse grupo que possui o plano funeral ficou explícito que, apesar de todo o sentimento de angústia e sofrimento que vivenciaram, a forma como falam sobre os acontecimentos da pandemia foi de uma forma mais tranquila, assim como, a fala dos entrevistados (que não possuem o plano) que associaram esse período como uma fase transformadora. O que leva a acreditar que, mesmo não tendo opiniões parecidas sobre o mesmo momento, ambos trataram esse assunto com mais leveza, a despeito de circunstâncias diversas.

No próximo ponto foi levantado o questionamento sobre quais cuidados são importantes para se pensar quando alguém próximo na família falece. Assim sendo, quatro dos cinco entrevistados citaram que possuíam o plano funerário e que é algo facilitador, como: "No meu caso, em particular, eu tenho plano, que facilita muito para esses momentos de tensão, que você fica desnorteado". O único que não citou o plano, falou da funerária: "Fazer esse contato, de fato, com a funerária, para cuidar da parte burocrática".

Ademais à essa questão abordada foram levantados assuntos paralelos (Anexo 1) aos que citaram que tinham plano funerário (quatro entrevistados), como, se o preço impactou na decisão final ambos disseram que não, visto às vantagens que o plano oferece, compensa. Como embasamento: "Eles me mostraram os diversos tipos de planos com diferentes valores e eu acabei escolhendo o que mais se adequava pra mim"; "Plano assistencial, eu acho legal, porque pelo menos eu não vou dar trabalho nessa parte de arrumar funerária. Os meus familiares já entram em contato direto com a funerária e eles já providenciam tudo". Adiante avançou-se para a questão do motivo da contratação, onde dois entrevistados citaram a experiência que tiveram com familiares e por terem que cuidar de todo o processo burocrático, como um deles citou: "Quando o meu pai faleceu, nós estávamos sem cabeça para resolver as coisas, então foi bem mais difícil resolver tudo". Os outros dois, mencionaram motivos diferentes, como: "Eu entrei para o plano assistencial por causa das minhas filhas, porque elas faziam faculdade e o plano dava desconto de faculdade"; e "Na verdade, quem fez o plano foi o meu pai quando a gente era criança e eu só continuei com o plano, porque ele sempre disse pra gente que 
era muito importante não ter que depender de outras pessoas". E, por fim, foi indagado se já tiveram plano em mais de uma empresa, três dos quatro disseram que só fizeram em uma empresa e mantiveram, o outro entrevistado mencionou que mudou porque a primeira empresa entrou em falência.

Ao refletir sobre todos esses assuntos de cuidados e desdobres dos que citaram o plano funerário, é notório que, aos que realizaram o plano devido às experiências passadas, eles resgataram na memória após contratarem um funeral e observarem a quantidade de processos que precisam fazer. Assim sendo, identificaram a necessidade de um plano, por meio da aprendizagem, transferindo confiança ao serviço do plano funerário. Agora, o entrevistado que citou a continuidade ao plano do pai remete, justamente, a presença dos fatores sociais, em relação à fala do pai, ao dizer que era importante ter um plano, por ele ter uma interferência direta e por ter valores e crenças próximas à filha, ela manteve o plano. Por último, o que realizou um plano, visando uma vantagem, quanto ao desconto para a faculdade de suas filhas, foi influenciado pelos fatores pessoais, que a empresa funerária identificou como oportunidade para atrair um novo público, mesmo que nesse caso seja indiretamente, o estudante (Kotler e Keller, 2012). Além disso, apesar do respondente que não mencionou ter o plano nessa questão, citou que o contato com a funerária deveria ser estabelecido para seguirem com os trâmites necessários, pode-se observar que, inconscientemente, ele já visualiza este serviço como um simplificador.

Com o propósito de captar a experiência com os serviços funerários desde a contratação até o sepultamento, essa questão foi abordada. Todos entrevistados apontaram todo o processo como satisfatório, de qualidade e tranquilidade. Conforme algumas falas: "Eu senti muito respeito e conforto com a experiência, apesar de dolorosa, foi confortável"; "Foi tranquila desde a hora que eu liguei pra funerária até a hora do sepultamento, tudo correto, sem problemas, não tive preocupação nenhuma"; "Sempre trataram com muito respeito e tive uma boa orientação, que faz toda a diferença, porque é um momento de dor, né?"; e "Sempre foram muito atenciosos, me deram o suporte total".

Em virtude dos resultados, nota-se que, ambos demonstram satisfação com os serviços prestados aos seus familiares. As empresas funerárias têm a necessidade de ter um acompanhamento constante do nível de satisfação dos clientes, uma vez que, o nível de satisfação ou insatisfação muda, podem acontecer consequências para a empresa. Fato que, Kotler e Keller (2012), mencionam a respeito do modelo de cinco etapas, no estágio do pós-compra, pois se o cliente tem suas expectativas superadas a chance de ele continuar 
com o serviço e até mesmo indicar, são enormes. Mas, vale destacar que, para a insatisfação o mesmo acontece.

Em sequência, foi perguntado como os entrevistados conseguem distinguir um seguro de vida de um plano funerário. Ambos entrevistados conseguiram definir alguma diferença entre esses serviços, tal como: "O plano funerário é conforto, apoio no momento em que a pessoa falece e tem esse auxílio da funerária. Já o seguro de vida é em relação ao valor financeiro, no caso, quando a pessoa falece, deixa um valor para uma família"; "O plano funerário você paga para que na hora que acontecer o óbito, você ter tranquilidade. O seguro de vida, você paga para quando você falecer, você deixar o valor pra alguém da sua família"; "O seguro de vida é um convênio que você faz tendo outras pessoas como beneficiárias, caso você faleça. O plano funerário já poderia ser utilizado tanto pelos beneficiários quanto pelo próprio contratante".

Outrossim, uma questão paralela foi empreendida a fim de complementar o tema seguro de vida e plano funerário, a qual consiste em compreender os aspectos que podem dificultar o processo de contratação de um plano funerário. Os respondentes acreditam que acontece devido à idade, resistência, falta de informação e por ainda ser um tabu falar sobre assuntos relacionados à morte. Tais como: "A juventude já é uma excludente para a aquisição de plano funeral”; "Acho que é por uma questão de tabu. As pessoas têm medo da morte e evitam falar sobre isso. Mas, é necessário falar sobre e pensar que esse momento vai chegar e o que pode ser feito para poupar um pouco o sofrimento na hora do falecimento; "Eu acredito que seja mais pela falta de informação das pessoas, porque as pessoas ficam pensando que se contratar vai dar azar, que tá esperando a morte de alguém".

Investigando-se as informações supracitadas fica compreensível como todos possuem o plano funerário, torna-se mais simples enxergar as oposições entre o plano funerário e o seguro de vida, já que, utilizam deste serviço e de suas vantagens. Dessa forma, as empresas funerárias têm a necessidade de estar alinhadas com os fatores psicológicos dos indivíduos, e constantemente, estar fortalecendo e salientando a memória das pessoas com a relevância e a particularidade dos planos funerários para os clientes e também para futuros clientes não criarem uma memória negativa do serviço, em caso de algum problema na prestação do serviço (Kotler e Keller,2012). Além disso, os entrevistados conseguem enxergar toda a visão que as pessoas que não possuem plano apresentam às pessoas. Contudo, os entrevistados mantem o 
plano funerário por compreenderem sua importância e não são influenciados nessa questão.

A pergunta seguinte foi efetuada apenas para o entrevistado que não havia mencionado que possuía o plano funerário, pois os demais já haviam mencionado sem serem questionados. O mesmo confirmou que possui o plano, como próprio expõe: "Eu fiz a opção de ter o plano desde cedo, por prevenção e condições financeiras, de saber que pode acontecer e não ter como resolver. Mas, nesses momentos, a gente não tem opção, tem que resolver, né? E acabar dependendo de ajuda, então eu tenho essa consciência de prevenção. Por isso, tenho o plano há bastante tempo". Nessa situação, os fatores pessoais de Kotler e Keller (2012) estão presentes, visto que, as decisões dele foi influenciada por circunstâncias econômicas.

E, por fim, a última questão foi abordado o que faria com que os entrevistados desistissem de continuar com o plano. Com 0 intuito de compreender as particularidades e analisar através das respostas, o que as empresas funerárias poderiam aperfeiçoar e/ou estarem atentas em suas empresas. Isto posto, observou-se que um entrevistado não desistiria, mas que mudaria de empresa, caso ele se mude para um local que a empresa não faça a cobertura. Como o próprio destacou: "Até no pior momento para se ter um plano funeral, ele é importante, porque você pode ficar doente e se acontecer alguma e você não ter o plano vai ficar pior ainda". Ademias, dos cinco entrevistados quatro alegaram que desistiriam por algum motivo, como mau atendimento e três respondentes por problemas financeiros.

Dessa forma, apesar de conseguirem observar a importância de um plano funeral para os momentos de perda, todavia, ainda não enxergam como um serviço insubstituível, visto que, por problemas financeiros não permaneceriam com o plano. É possível relacionar esse fato com a pirâmide de Maslow, dado que, os entrevistados têm prioridades em satisfazer suas necessidades mais básicas, com isso, os interesses e necessidades vão sofrendo transformações (Kotler e Keller, 2012). Entretanto, o marketing das empresas deve se conectar completamente com seus clientes, com o objetivo de assimilar o comportamento de compra do consumidor e os fatores que mais influem o seu público. 


\section{Conclusões e recomendações para novos estudos}

A presente pesquisa teve como propósito investigar o comportamento dos indivíduos quanto ao reconhecimento da necessidade da obtenção ou da negação aos planos funerários, revelando as percepções e experiências a cerca de temáticas do mercado funerário. Além disso, expor as motivações e os desafios que esse mercado enfrenta em relação a venda destes planos. Com a intenção de cumprir a finalidade do estudo, buscou-se os conceitos do processo de decisão de compra, tanto pelo modelo das etapas (Kotler e Keller, 2012) quanto pelas categorias de tomada de decisão (Solomon, 2016) e também o conteúdo da análise de mercados consumidores, envolvendo os fatores de interferência (Kotler e Keller,2012).

Sucessivamente, foram realizadas entrevistas individuais qualitativas, com um roteiro semiestruturado, para obter respostas mais detalhadas e profundas a cerca dos temas sobre o mercado. Ao todo, foram 10 pessoas entrevistadas, via WhatsApp por conversas de áudio, que estavam de acordo com o perfil pretendido, isto é, pessoas que possuem o plano funerário e pessoas que não possuem o plano. Os dados foram tratados através da transcrição de alguns trechos que foram ponderados pela análise de conteúdo. Isto posto, todos os dados obtidos por meio das entrevistas e conceitos de marketing reúnem diversas ideias para as empresas do setor funerário, a fim de identificar o comportamento de possíveis clientes e adaptar suas estratégias de comunicação e comercialização com o intuito de conquistar esse público.

Baseado nas informações sobre os cuidados necessários para um falecimento na família, pôde-se apreender que, todos os entrevistados, os que possuem o plano funerário e os que não possuem, reconhecem tanto o problema quanto a necessidade das questões burocráticas de um óbito. Mas, a diferença das pessoas que não possuem o plano, é que não conseguem perceber a real necessidade de contratar um plano funerário, apenas inconscientemente. Por outro lado, as pessoas que possuem o plano conseguem identificar a necessidade de possui-lo com mais clareza, visto que esse grupo já passou por todos os processos de decisão de compra, ou seja: houve o reconhecimento do problema e a necessidade, buscou informações a 
cerca do plano, avaliou as alternativas dentro de sua realidade e realizou a decisão de compra. Diferentemente do grupo que não tem plano, sabem do problema e da necessidade, mas não conseguem enxergar esse serviço como uma oportunidade ao ponto de contratar, ou seja, param na primeira fase do processo de decisão de compra.

Dessa forma, as empresas funerárias devem investir em pesquisas constantemente sobre os fatores que interferem na preferência de compra de cada consumidor, ou seja: os culturais, sociais, pessoais e psicológicos. Com a intenção de conhecer mais as razões desse público que não possui o plano e elaborar estratégias de comunicação que aproxime essa necessidade de sua realidade e para que essas pessoas possam dar continuidade ao processo de decisão de compra. Desse modo qualquer pessoa diante de um mesmo estímulo pode ter percepções e comportamentos diferentes diante da mesma situação. Logo compete a empresa atrair esse público estimulando cada um desses estímulos.

Após a análise de ambos os grupos perceberem o problema e a necessidade quanto aos cuidados quando ocorre um falecimento, independentemente de ter ou não um plano. Por conseguinte, houve a abordagem de suas próprias experiências nesse momento, com o objetivo de alcançar informações mais aprofundadas. Dessa forma, percebeu-se dois entrevistados que nunca tiveram uma experiência própria em relação à contratação do serviço funeral, ambos citaram experiências de pessoas próximas. Por isso, é interessante mostrar que, os dois respondentes que citaram essas experiências, ambos já pensaram em ter um plano funerário. Mas, que não foi concluído por motivos distintos. À vista disso, é aparente que as experiências de outras pessoas sejam positivas ou negativas, impactam no anseio de possuir um plano funerário. Por outro lado, os entrevistados que citaram ter possuído uma experiência satisfatória nesses serviços têm grande impacto na indicação da empresa para outras pessoas. Já que, revelaram, nas entrevistas, terem pedido indicação de empresas funerárias à conhecidos.

Desse modo, compete às empresas identificarem esses motivos e planejar campanhas que esclareçam as inseguranças do grupo sem plano funerário. Além disso, as empresas necessitam estar em um sucessivo acompanhamento de suas prestações de serviço. Visto que, as experiências de pessoas próximas com essa assistência funeral, impactam diretamente na decisão de outras. Isto significa que, o marketing boca a boca é extremamente eficiente para esse tipo de serviço. 
Sobre a distinção de um seguro de vida de um plano funerário, a pesquisa indicou que as pessoas que não têm o plano funerário encontram mais dificuldades para determinar essa diferença. No entanto, o grupo que tem o plano consegue apontar o contraste entre um serviço e outro. De fato, as pessoas que possuem o plano conseguem elaborar esse paralelo por usarem este serviço e seus benefícios. Diferentemente, dos que não têm plano, já que, não detêm de um conhecimento aprofundado sobre ambos os serviços pelo fato de não os usufruírem. Com isso, as empresas devem utilizar mais os meios de comunicação a fim de despertar o interesse dos indivíduos conhecerem mais sobre esses assuntos.

Por fim, sobre os pontos que podem dificultar o processo de contratação de um plano funerário. É possível notar que, os fatores que atrapalham a contratação deste serviço estão profundamente interligados aos fatores culturais e pessoais, ou seja, aos valores e crenças, envolvendo também ao estágio de ciclo de vida das pessoas e quanto às circunstâncias econômicas. Dessa maneira, é de extrema importância que as empresas conheçam esses dois grupos, com plano e sem plano. Com o intuito de criar debates sobre esses pensamentos que são gerados, devido a falta de informação, a resistência e o tabu, como mencionado pelos entrevistados.

\subsection{Sugestões e recomendações para novos estudos}

Como desdobramentos futuros, essa linha de estudo pode ser desenvolvida através de uma investigação sob uma visão mais ampla, através de uma pesquisa quantitativa, a fim de, alcançar uma quantidade maior de respondentes tanto do Rio de Janeiro quanto de outros estados. Dado que, poderá ser feito uma análise do processo de decisão de compra por estado, averiguando as diferenças culturais no comportamento do consumidor em relação aos planos funerários.

Outra forma de aprofundamento da pesquisa para compreender as necessidades desse mercado seria por meio de uma outra ótica, ou seja, sob a perspectiva dos empresários funerários. Dessa maneira, será possível tratar sobre o mesmo tema, quanto aos desafios e as motivações da contratação de planos funerários, mas por uma visão mais estratégica dos gestores. Ademais, essa forma tem potencial tanto para diretores do estado do Rio de Janeiro quanto para outros estados. 


\section{Referências}

ANDRADE, H. "É bom que a sociedade não teste nosso limite, diz setor funerário". CNN Brasil, São Paulo, 12 de março de 2021. Disponível em: $<$ https://www.cnnbrasil.com.br/saude/2021/03/12/e-bom-que-a-sociedade-naoteste-nosso-limite-diz-setor-funerario>. Acesso em: 03 de maio de 2021.

BAUER, M; GASKELL, G. "Pesquisa qualitativa com texto, imagem e som: um manual prático". $7^{\text {an }}$ edição. Rio de Janeiro: Vozes, 2008. p.189-217.

BION, B.; LEITE, P. "Cuidados com idosos vão além da vida". Estadão. Disponível em: <https://infograficos.estadao.com.br/focas/planeje-suavida/cuidados-com-idosos-vao-alem-da-vida>. Acesso em: 05 de maio de 2021.

BORGES, H. "Aumento na demanda volta a assustar setor funerário em 2021". O Povo, 29 de março de 2021. Disponível em: <https://www.opovo.com.br/coronavirus/2021/03/29/aumento-na-demanda-voltaa-assustar-setor-funerario-em-2021.html>. Acesso em 05 de maio de 2021.

KOTLER, P; KELLER, K. “Administração de marketing”. 14" edição. São Paulo: Pearson Education do Brasil, 2012. p. 179-186.

OCHOA, C. "Amostragem não probabilística: amostragem por conveniência". Netquest, 21 de outubro de 2015. Disponível em: < https://www.netquest.com/blog/br/blog/br/amostra-conveniencia>. Acesso em: 04 de outubro de 2021.

OLIVEIRA, A., FILHO, C., RODRIGUES, C. O processo de construção dos grupos focais na pesquisa qualitativa e suas exigências metodológicas. ANPAD, Rio de Janeiro, setembro de 2007. Disponível em: < http://www.anpad.org.br/admin/pdf/EPQ-A2615.pdf>. Acesso em: 04 de outubro de 2021.

OLIVEIRA, T. "Amostragem não probabilística: Adequação de situações para uso e limitações de amostrar por conveniência, julgamento e quotas". FECAP, v. 2, n.3, 2001.

PRIMAVERAS. "Qual a diferença entre plano funerário e seguro de vida?". São Paulo, 2020. Disponível em: < https://blog.primaveras.com.br/planofunerario-2/>. Acesso em: 29 de outubro de 2021.

SOLOMON, M. "O comportamento do consumidor: comprando, possuindo e sendo". 11 a edição. Porto Alegre: Bookman, 2016. p. 37-68. 


\section{Anexo 1}

\section{PESSOAS QUE NÃO TÊM PLANO}

\begin{tabular}{|c|c|c|}
\hline TEMA CENTRAL & $\begin{array}{l}\text { QUESTIONAMENTOS } \\
\text { PARALELOS }\end{array}$ & OBJETIVO \\
\hline $\begin{array}{c}\text { O que o número de óbitos no país, } \\
\text { devido a pandemia, gerou em } \\
\text { você? Quais sentimentos e/ou } \\
\text { sensações? }\end{array}$ & & $\begin{array}{l}\text { Entender como as pessoas se sentem } \\
\text { durante a pandemia, tendo em vista o } \\
\text { excessivo número de mortes no país. }\end{array}$ \\
\hline $\begin{array}{l}\text { Quais cuidados são importantes } \\
\text { para se pensar quando alguém } \\
\text { próximo à família falece? }\end{array}$ & & $\begin{array}{l}\text { Identificar quais medidas os entrevistados } \\
\text { têm nesses momentos e se irão citar os } \\
\text { planos funerários ou não. }\end{array}$ \\
\hline $\begin{array}{l}\text { Como foi a sua experiência com os } \\
\text { serviços funerários desde a } \\
\text { contratação ao sepultamento? O } \\
\text { que gostou? O que não gostou? }\end{array}$ & $\begin{array}{l}\text { Como você procura por } \\
\text { esse serviço quando } \\
\text { precisa? } \\
\text { Já contratou empresas } \\
\text { funerárias diferentes para } \\
\text { outros funerais r ou } \\
\text { contrata sempre a } \\
\text { mesma? }\end{array}$ & $\begin{array}{l}\text { Observar quais foram as experiências com o } \\
\text { serviço funerário em si, ou seja, quais foram } \\
\text { os pontos que mais e menos gostaram do } \\
\text { serviço (o contato com esse serviço); } \\
\text { abordar como as pessoas procuram por } \\
\text { esse serviço; entender se procuram } \\
\text { empresas diferentes sempre que precisam } \\
\text { ou se mantém sempre a mesma empresa. }\end{array}$ \\
\hline $\begin{array}{c}\text { Você já pensou alguma vez em ter } \\
\text { um plano funerário? }\end{array}$ & $\begin{array}{l}\text { O que te fez desistir de } \\
\text { ter? } \\
\text { O preço impactou na sua } \\
\text { decisão? }\end{array}$ & $\begin{array}{c}\text { Entender se em algum momento já } \\
\text { cogitaram a ideia de ter um plano, mesmo } \\
\text { que tenham decidido não ter esse serviço. } \\
\text { Além disso, compreender também o motivo } \\
\text { pelo o qual os fizeram desistir, questionando, } \\
\text { posteriormente, se um dos motivos foi o } \\
\text { preço. }\end{array}$ \\
\hline $\begin{array}{l}\text { Como você consegue diferenciar } \\
\text { um seguro de vida de um plano } \\
\text { funerário? }\end{array}$ & & $\begin{array}{l}\text { Averiguar se as pessoas sabem a diferença } \\
\text { entre esses dois distintos mercados. }\end{array}$ \\
\hline $\begin{array}{l}\text { Quais aspectos você acredita que } \\
\text { dificultam o processo de } \\
\text { contratação de um plano } \\
\text { funerário? }\end{array}$ & & $\begin{array}{c}\text { Captar o que eles acreditam se existe algo } \\
\text { ou não que atrapalha a venda de planos } \\
\text { funerários }\end{array}$ \\
\hline
\end{tabular}


PESSOAS QUE TÊM PLANO

\begin{tabular}{|c|c|c|}
\hline TEMA CENTRAL & $\begin{array}{l}\text { QUESTIONAMENTOS } \\
\text { PARALELOS }\end{array}$ & OBJETIVO \\
\hline $\begin{array}{l}\text { O que o número de óbitos no país, } \\
\text { devido a pandemia, gerou em } \\
\text { você? Quais sentimentos e/ou } \\
\text { sensações? }\end{array}$ & & $\begin{array}{l}\text { Entender como as pessoas se sentem } \\
\text { durante a pandemia, tendo em vista o } \\
\text { excessivo número de mortes no país. }\end{array}$ \\
\hline $\begin{array}{l}\text { Quais cuidados são importantes } \\
\text { para se pensar quando alguém } \\
\text { próximo à família falece? }\end{array}$ & $\begin{array}{l}\text { Devido a contratação dos } \\
\text { serviços funerários, a } \\
\text { questão } \quad \text { financeira } \\
\text { impacta nesse momento? } \\
\text { Por qual motivo você } \\
\text { decidiu ter o plano } \\
\text { funerário? } \\
\text { O preço impactou na sua } \\
\text { decisão? } \\
\text { Já teve plano funerário em } \\
\text { empresas diferentes? }\end{array}$ & $\begin{array}{l}\text { Identificar quais medidas os entrevistados } \\
\text { têm nesses momentos e se irão citar os } \\
\text { planos funerários ou não. } \\
\text { Obs.: As três últimas perguntas paralelas } \\
\text { só serão realizadas caso o entrevistado } \\
\text { diga que tem o plano funerário. Caso não } \\
\text { mencione, o assunto será levantado no } \\
\text { tema } 5 .\end{array}$ \\
\hline $\begin{array}{l}\text { Como foi a sua experiência com os } \\
\text { serviços funerários desde a } \\
\text { contratação ao sepultamento? O } \\
\text { que gostou? O que não gostou? }\end{array}$ & $\begin{array}{l}\text { Como você procura por } \\
\text { esse serviço quando } \\
\text { precisa? } \\
\text { Já contratou empresas } \\
\text { funerárias diferentes para } \\
\text { outros velórios ou contrata } \\
\text { sempre a mesma? }\end{array}$ & $\begin{array}{l}\text { Observar quais foram as experiências com } \\
\text { o serviço funerário em si, ou seja, quais } \\
\text { foram os pontos que mais e menos } \\
\text { gostaram do serviço (o contato com esse } \\
\text { serviço); abordar como as pessoas } \\
\text { procuram por esse serviço; entender se } \\
\text { procuram empresas diferentes sempre } \\
\text { que precisam ou se mantém sempre a } \\
\text { mesma empresa. }\end{array}$ \\
\hline $\begin{array}{l}\text { Como você consegue diferenciar } \\
\text { um seguro de vida de um plano } \\
\text { funerário? }\end{array}$ & $\begin{array}{l}\text { Quais aspectos você acha } \\
\text { que dificultam o processo } \\
\text { de contratação de um } \\
\text { plano funerário? }\end{array}$ & $\begin{array}{c}\text { Averiguar se as pessoas sabem a } \\
\text { diferença entre esses dois distintos } \\
\text { mercados. }\end{array}$ \\
\hline $\begin{array}{l}\text { Você já pensou alguma vez em ter } \\
\text { um plano funerário? }\end{array}$ & $\begin{array}{l}\text { Por qual motivo você } \\
\text { decidiu ter o plano } \\
\text { funerário? } \\
\text { O preço impactou na sua } \\
\text { decisão? }\end{array}$ & $\begin{array}{l}\text { Entender como decidiram ter um plano. } \\
\text { Além disso, compreender se o preço } \\
\text { impacta na escolha da empresa ou então } \\
\text { prezam a qualidade do serviço. }\end{array}$ \\
\hline
\end{tabular}


O que te faria desistir de continuar com o plano?
O que você gostaria de ter nesse plano que não tem? $\mathrm{O}$ que facilitaria?
Captar o que eles desejariam que tivesse num plano funerário, que atualmente não tem. 